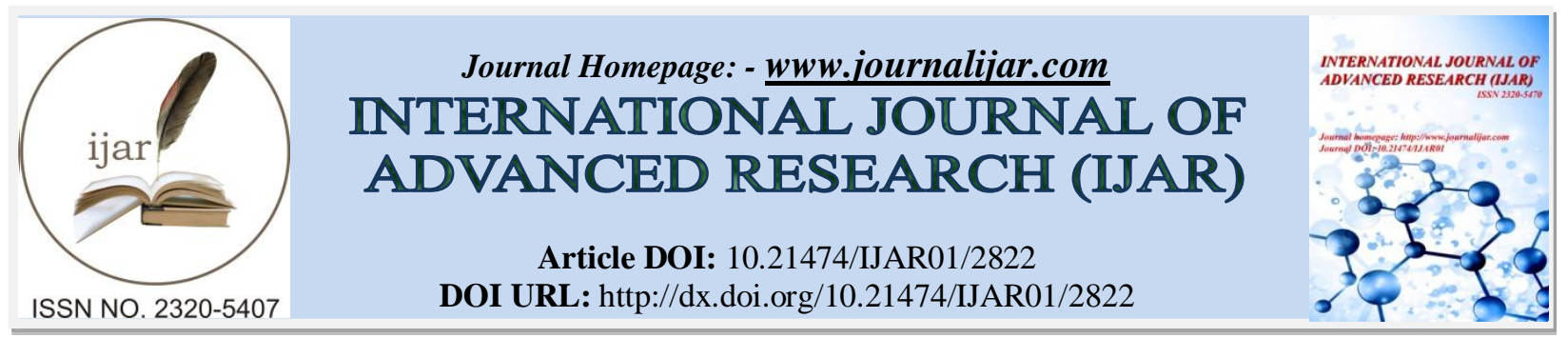

\title{
RESEARCH ARTICLE \\ Utility of Amplification Refractory Mutation System PCR for the detection of JAK2 mutation in Chronic Myeloproliferative Disorders.
}

\author{
Rashid Mir ${ }^{1}$, Abu-Duhier FM ${ }^{1}$, Jamsheed $\mathbf{J}^{1}$,Fawzia Sharaf ${ }^{2} \&$ Nabil Burrow ${ }^{2}$ \\ 1. Prince Fahd Bin Sultan Research chair, Division of cancer Molecular Genetics, Department of Medical Lab Technology, \\ Faculty of Applied Medical Sciences, University of Tabuk, Kingdom of Saudi Arabia. \\ 2. Deparment of Clinical Pathology, King Fahad Special Hospital, Ministry of Health Kingdom of Saudi Arabia.
}

\section{Manuscript Info}

Manuscript History

Received: 13 June 2016

Final Accepted: 15 October 2016

Published: January 2017

Key words:-

ARMS-PCR: Amplification refractory mutation system-PCR, PASA: PCR

amplification of specific alleles

JAK2 V617F,

\section{Abstract}

Detection of the JAK2 V617F mutation is helpful in differential diagnosis, prognosis, and predication of therapeutic response in CMPD disorders. Because the mutation can be present in a small proportion of granulocytic populations in MPD patients, a highly sensitive detection method is required. The study was aimed to optimize ARMS-PCR for the detection of JAK2 V617F mutations .This study was conducted at Prince Fahd Bin Sultan Research Chair .Fifty subjects were registered from the King Khaled Hospital of Tabuk -Northwestern part of Saudi Arabia among which 25 newly diagnosed MPD patients and 25 healthy controls. DNA was extracted done using DNA extraction Kit from Qiagen .ARMS was optimized in which a a primers were designed in such a way that it is able to discriminate among templates that differ by a single nucleotide residue in one tube reaction.Both cases and controls were tested for JAK2 mutations by ARMS-PCR. Demographic data, spleen size, hemoglobin level, white blood cell and platelet counts were recorded. Independent sample t-test was used to study the correlation of JAK2 mutations with age, haemoglobin, blood counts and spleen size. Fisher's exact test was applied to compare disease progression in mutation positive and negative cases. This study was conducted on 25 newly diagnosed MPD patients among which 17 were polycythemia vera,5 Essential thrombocytopenia and 3 primary myelofibrosis and 25 healthy controls. Both cases and controls were tested for JAK2 mutations by ARMS-PCR. The JAK2 mutation was detected in 17/25 samples among which 13 were Polycythemia Vera, 02 from Essential thrombocythemia, 01 from Primary myelofibrosis. The JAK2 mutation was not detected in any of the healthy controls by ARMS-PCR. The main advantage of ARMS was that the amplification step and the diagnostic steps were combined, in that the presence of an amplified product indicates the presence of a particular allele and vice versa. For routine diagnosis, this characteristic of ARMS means that it is a very time-efficient method.It was concluded that the ARMS-PCR assay optimized allows the discrimination between homozygous and heterozygous individuals with the JAK2 V617F mutation and has a key role in acting as a reliable screening test for the presence or absence of the mutation in individuals with MPDs. The test will be potentially useful to follow minimal residual disease when targeted therapies against JAK2 kinase become available. The test is therefore a simple, fast, and inexpensive procedure that does not entail any special equipment other than a thermocycler.

\section{Introduction:-}

Myeloproliferative neoplasms (MPNs) are multipotent hematopoietic stem cell disorders characterized by uncontrolled proliferation of maturing blood cells ${ }^{1}$. Among its types, Chronic myeloid leukemia (CML) is the most common MPN, followed by polycythemia vera (PV), essential thrombocythemia (ET), and idiopathic myelofibrosis (IMF). The pathogenesis of myeloproliferative disorders (MPD), is still largely unknown except the chronic myeloid leukemia (CML), where the presence of the $\mathrm{t}(9 ; 22) \mathrm{Ph}$ chromosome and of the underlying molecular abnormality has been known for decades and ultimately led to the development of target-specific drugs, the molecular lesion(s) at the basis of the other MPD has remained elusive. ${ }^{2-4} \mathrm{JAK} 2$ is a cytoplasmic tyrosine kinase that plays an essential role in the signaling pathways of cytokines and growth factors. An acquired $\mathrm{G} \rightarrow \mathrm{T}$ point mutation in exon 12 of the gene encoding the Janus tyrosine kinase 2 (JAK2), leading to amino acid substitution of phenylalanine for a highly conserved valine (V617F), in

Corresponding Author:- Rashid Mir.

Address:- Prince Fahd Bin Sultan Research chair, Division of cancer Molecular Genetics, Department of Medical Lab Technology, Faculty of Applied Medical Sciences, University of Tabuk, Kingdom of Saudi Arabia. 
the JH2 pseudo-kinase domain, renders JAK2 kinase constitutively active and leads to cell proliferation in the absence of the growth factors ${ }^{5-6} . \mathrm{I} n$ vivo expression of $J A K 2^{\mathrm{V} 617 \mathrm{~F}}$ in a murine transplant model induced erythrocytosis ${ }^{7}$. the mechanism of activation of JAK2 kinase activity by mutations in the JAK2 signalling pathway as depicted in figure 1. The JAK2V617F and JAK2 exon 12 mutant kinases bind cytokine receptors and are phosphorylated in the absence of ligand, and lead to ligand-independent activation of downstream signaling pathways.

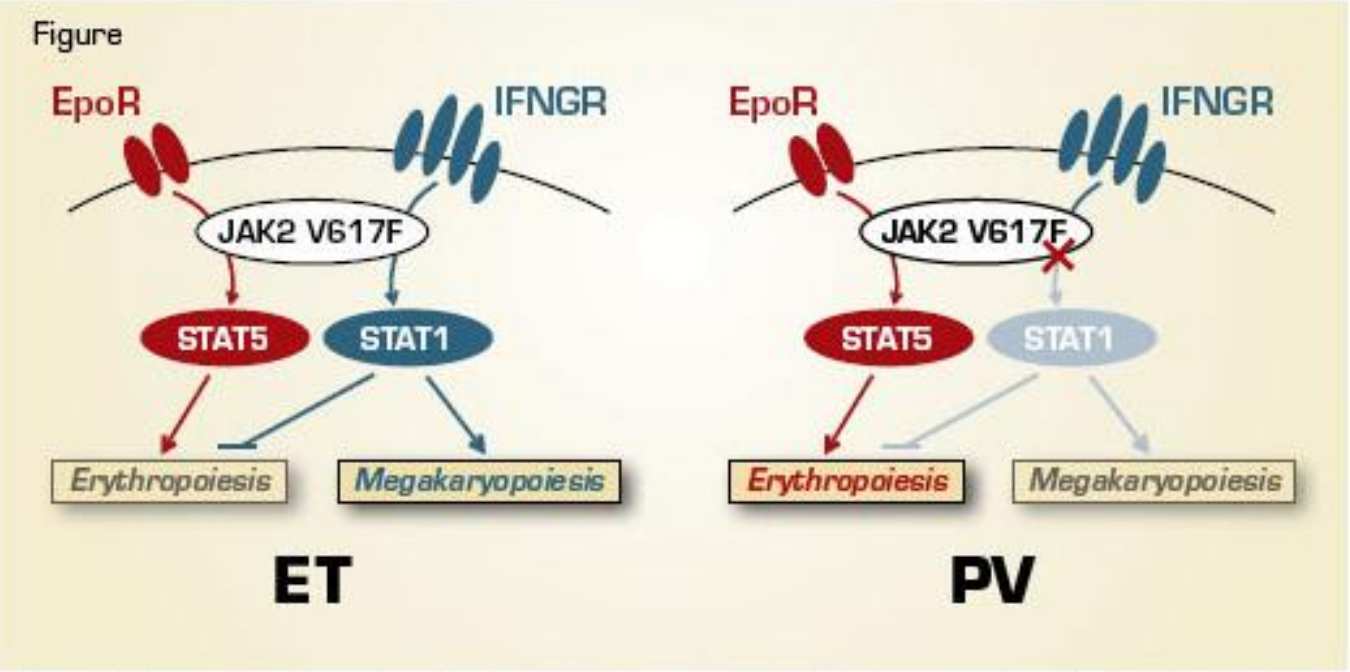

Figure 1 The mechanism of activation of JAK2 kinase activity by mutations in the JAK2 signaling pathway

The JAK2 mutation has been detected in 65 to $97 \%$ of patients with polycythemia vera, 23 to $57 \%$ of those with essential thrombocythemia (ET), and 30 to $57 \%$ of idiopathic myelofibrosis. ${ }^{7-8}$ JAK2 mutation is absent in normal individuals, in patients with secondary erythrocytosis and thrombocytosis, or in patients with chronic myelogenous leukemia; detection of the mutation thus aids in differential diagnosis in cases with similar clinicopathological features. ${ }^{9}$ Methods for detection of $J A K 2^{\mathrm{V} 617 \mathrm{~F}}$ mutation based on the analysis of genomic DNA obtained from peripheral blood granulocytes have been devised and already entered the clinical practice. Because V617F is an acquired mutation that can be present in a small proportion of granulocytic populations in some cases, especially of ET, a highly sensitive detection method is essential $^{10}$.Methodologies reported in the literature include direct sequencing, ${ }^{6}$ PCR-restriction fragment length polymorphism, ${ }^{10}$ allele-specific polymerase chain reaction (PCR), ${ }^{11}$ pyrosequencing, ${ }^{12}$ and amplification refractory mutation system (ARMS)-PCR. ${ }^{13}$ The modified assay detects mutation with a highly reproducible analytic sensitivity of 0.05 to $0.1 \%$, making it suitable for the detection of low levels of $J A K 2$ mutation. The test will be potentially useful to follow minimal residual disease when targeted. The merits and demerits of the various methods used for JAK2 mutation detection have been by studied described for principles and potential clinical utilities of each assay ${ }^{14}$. Some have adapted the use of mRNA as the basis for testing for JAK2 mutations and have shown that RNA allows more sensitive detection of mutations than does DNA at early stages of disease The use of RNA rather than DNA provides the additional advantage of capturing abnormalities in platelets and detecting alternatively spliced transcripts ${ }^{15}$.The reported frequency of $J A K 2^{\mathrm{V} 617 \mathrm{~F}}$ mutation is around $80 \%$ (range, 65-100\%) in PV, 40\% (range, 23-57\%) in ET and 55\% (range, $35-95 \%)$ in IM patients ${ }^{16} . J A K 2^{\mathrm{V} 617 \mathrm{~F}}$ mutation is found in either the heterozygote or the homozygote status, the latter arising from mitotic recombination; there are significant differences in the incidence of homozygosity, which involves about 30\% of patients in PV and IM and less than 4\% in ET.

There are indications that the clinical phenotype might be dependent on the proportion of mutated allele, as the expression levels of some aberrantly regulated genes in MPD, such as $P R V-1$ or $N F-E 2$, have been found higher in homozygote than in heterozygote patients. ${ }^{17-18}$ In a large survey on ET patients, the presence of the mutation was associated to clinical and biological features suggestive of a PV-like disease, thus supporting the view that these two disorders represent a biological continuum; furthermore, according to the presence of the JAK2 ${ }^{\mathrm{V} 617 \mathrm{~F}}$ mutation, ET patients could be divided into two distinct subpopulations characterized by different disease presentation, clinical complications and response to therapy. We aimed to optimize the diagnostic values of the ARMS-PCR method for detecting mutations in exon 14 of the JAK2 gene to diagnose myeloproliferative disorders. 


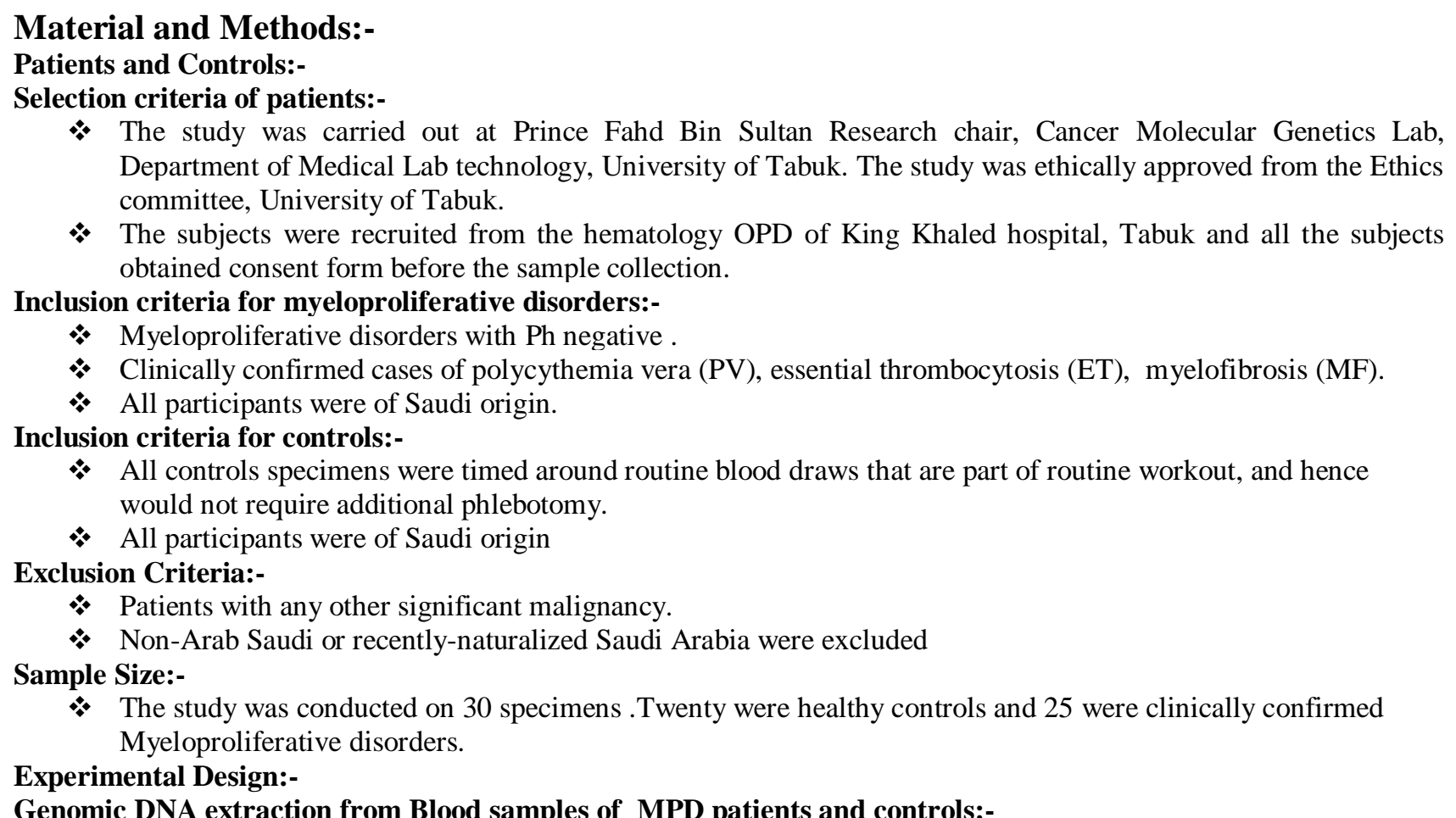

The Blood samples were collected by venipuncture in EDTA tubes from MPD patients and healthy controls. The DNA extraction was done by using DNeasy Blood Kit cat 69506 from Qiagen as per the manufactures instructions. The QIAamp DNA Blood Mini Kit provides silica-membrane-based DNA purification. The QIAamp DNA Blood Mini Kit was designed for processing up to $200 \mu \mathrm{l}$ fresh or frozen human whole blood. QIAamp Mini spin columns can be easily processed in a centrifuge or on vacuum manifolds. Purification of DNA using the QIAamp DNA Blood Mini Kit was fully automated on the QIAcube .The DNA extracted was dissolved in nuclease-free water, and stored at $4^{\circ} \mathrm{C}$ until use. The DNA quality and yield was assessed using Nanodrop (optical density) and agarose gel electrophoresis

Amplification ARMS primers for the JAK2 mutation:-

ARMS-PCR was performed in a final volume of $5 \mathrm{uL}$ containing $2 \mathrm{uL}$ of 50ng genomic DNA, $12.5 \mathrm{uL}$ of PCR-master mix purchased from Epigentek (USA), $0.25 \mathrm{uL}$ of $25 \mathrm{pmol} / \mathrm{L}$ of each primer (Table 1) The Methylamp Taq 5x PCR Mix was premixed ready-to-use solution containing all reagents required for PCR (except template, primers and water). Methylamp Taq DNA polymerase,5x Reaction Buffer: $10.4 \mathrm{M}$ Tris-HCl, $0.1 \mathrm{M}$ (NH4)2SO4, 0.1\% w/v Tween-20 ,12.5 $\mathrm{mM} \mathrm{MgCl2}$ : 1x PCR solution - $2.5 \mathrm{mM} \mathrm{MgCl} 2,1 \mathrm{mM}$ dNTPs of each and remaining nuclease free $\mathrm{ddH}_{2} \mathrm{O}$ as depicted in Table 2. Finally the $2 \mathrm{ul}$ of DNA was added from each patient and control separately. The thermo cycling conditions for the PCR amplification of ARMS primers for JAK2 mutation were initial denaturation at $95^{\circ} \mathrm{C}$ for 10 minutes followed by 40 cycles $95{ }^{\circ} \mathrm{C}$ for $45 \mathrm{sec}, 57.9^{\circ} \mathrm{C}$ for $45 \mathrm{sec}$, and $72{ }^{\circ} \mathrm{C}$ for $45 \mathrm{sec}$ followed by the final extension at $72{ }^{\circ} \mathrm{C}$ for 10 minutes.

Table 1:- Primers designed for ARMS PCR

\begin{tabular}{|l|l|c|c|}
\hline \multicolumn{1}{|c|}{ Primer } & \multicolumn{1}{|c|}{ Sequence } & Annealing Temp & PCR product \\
\hline Forward outer & 5'-TCCTCAGAACGTTGATGGCAG- 3' & 57.9 & $463 \mathrm{bp}$ \\
\hline Reverse outer & 5'-ATTGCTTTCCTTTTTCACAAGAT-3' & & \\
\hline Forward wt & 5'-GCATTTGGTTTTAAATTATGGAGTATATG-3' & & $229 \mathrm{bp}$ \\
\hline Reverse mut & 5'-GTTTTACTTACTCTCGTCTCCACAAA-3' & & $279 \mathrm{bp}$ \\
\hline
\end{tabular}


Table 2:- Preparation of PCR coattail.

Finally 2 ul DNA was added.

\begin{tabular}{|l|c|c|}
\hline \multicolumn{1}{|c|}{ Reagent } & $\mathbf{1 x}$ & $\mathbf{5 x}$ \\
\hline PCR master mix & $5 \mathrm{ul}$ & $25 \mathrm{ul}$ \\
\hline Forward outer & $0.25 \mathrm{ul}$ & $1.25 \mathrm{ul}$ \\
\hline Reverse outer & $0.25 \mathrm{ul}$ & $1.25 \mathrm{ul}$ \\
\hline Forward wild & $0.25 \mathrm{ul}$ & $1.25 \mathrm{ul}$ \\
\hline Reverse mutant & $0.25 \mathrm{ul}$ & $1.25 \mathrm{ul}$ \\
\hline Nuclease free water & $17.0 \mathrm{ul}$ & $85 \mathrm{ul}$ \\
\hline Total volume & $23 \mathrm{ul}$ & $110 \mathrm{ul}$ \\
\hline
\end{tabular}

\section{Results and Discussion:-}

The purity of DNA extracted was checked by using Nanodrop1000 Spectrophotometer from Thermo .All DNA samples were screened for purity by measuring optical density $(\mathrm{OD})$ at $260 \mathrm{~nm}\left(\mathrm{OD}_{260}\right)$ and $280 \mathrm{~nm}\left(\mathrm{OD}_{280}\right)$. DNA concentration (ug/ml) was calculated based on the $\mathrm{OD}_{260}$ reading .A ratio of $\sim 1.8$ was generally accepted as "pure" for DNA .The optimal rang of ratio obtained were 1.7-2 .The DNA 260/230: 1.7-2; Pure DNA must have a 260/280 ratio between 1.8 and 2 . The quality of DNA was checked by running in $1 \%$ gel electrophoresis as shown in figure 2.

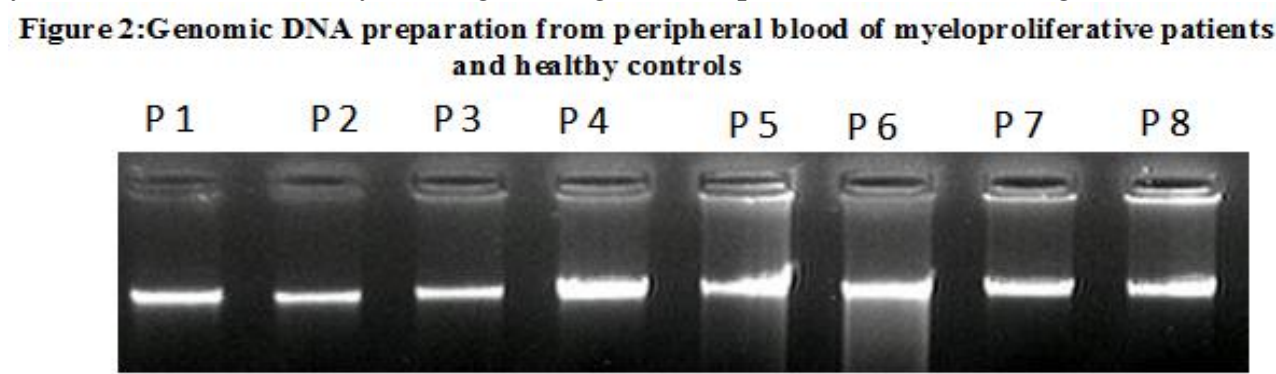

a). Genomic DNA preparation from peripheral blood of myeloprolif erative patients

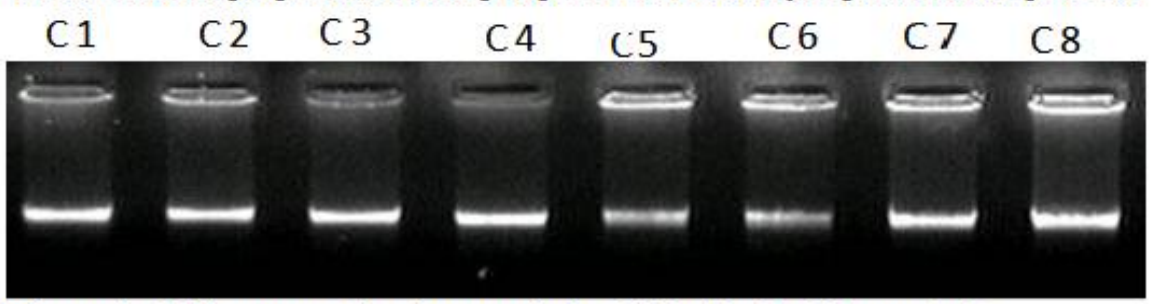

b). Genomic DNA preparation from peripheral blood of healthy controls

\section{Amplification Refractory Mutation System (ARMS-PCR) for JAK2V617F mutation:-}

Tetra-primer ARMS-PCR was established for the analysis of single nucleotide polymorphisms (SNP), which employs two primer pairs to amplify, respectively, the two different alleles of an SNP in a single PCR reaction. Two forward and two reverse primers are used in different combinations to generate three potential PCR products. Primers FO and RO flank the exon 14 of the $J A K 2$ gene, resulting in a band of $463 \mathrm{bp}$ to control for DNA quality and quantity. Primers Fwt and RO amplify a wild-type allele, generating a band of $229 \mathrm{bp}$, and primers FO and Rmt generate a band of $279 \mathrm{bp}$ from the mutant allele as shown in figure 3 . 


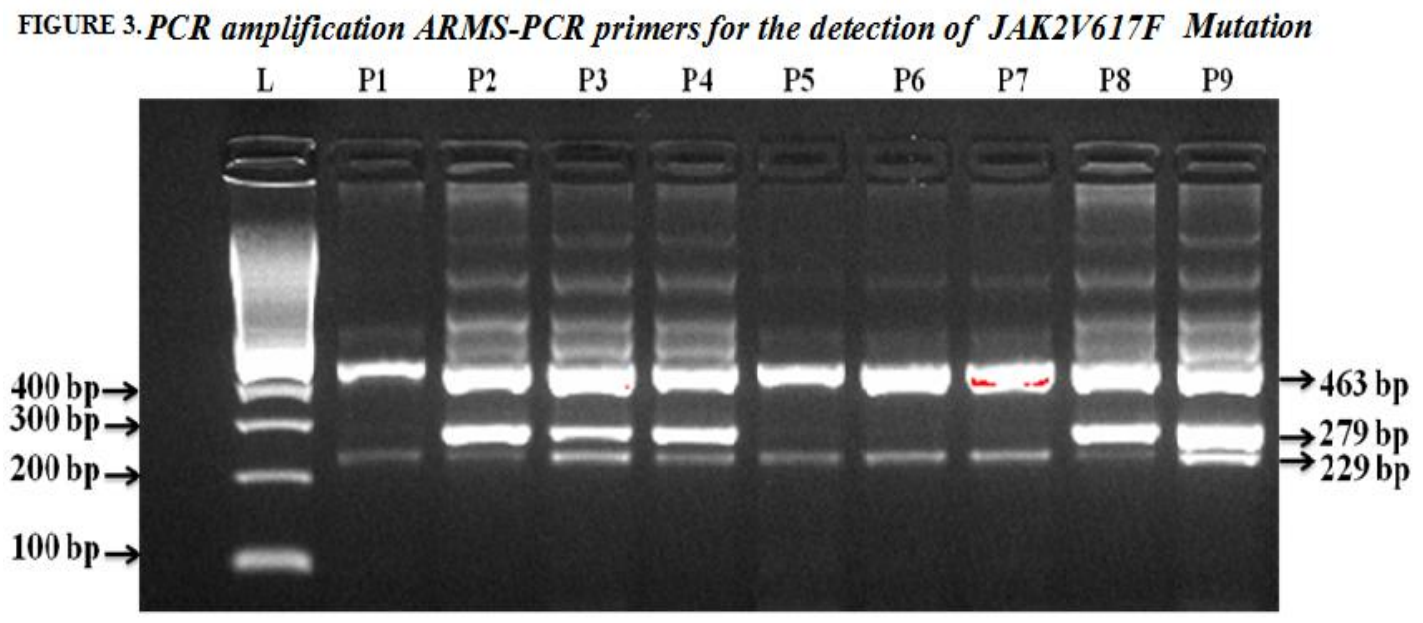

JAK2 (V617F) mutation analysis by ARMS PCR in leukemia patients:

$\mathrm{L}=100 \mathrm{bp}$ Ladder.

$\mathrm{P} 1, \mathrm{P} 5, \mathrm{P} 6$ and $\mathrm{P} 7=$ Mutation Negative.

$\mathrm{P} 2, \mathrm{P} 4, \mathrm{P} 4, \mathrm{P} 8$ and $\mathrm{P9}=$ Mutation Positive.

The intended mismatches in Fwt and Rmt are shown in lowercase, and genotype-specific nucleotides are underlined as shown in figure 4.The amplification Refractory Mutation Screening (ARMS) PCR permits a single base change to be detected under ideal PCR conditions. This is ideal for detection of the single base $G \rightarrow T$ transversion associated with the JAK2 mutation in question. The ARMS-PCR technique uses 4 primers as shown in figure 4 as follows; a forward outer primer, a reverse outer primer a forward inner wild type specific primer and a reverse inner mutant specific primer. It requires two temperature programs during the PCR reaction. Due to the positioning of the outer primers at varying distance from the site of the mutation there is the generation of three fragments in this example in a heterozygote: two small allele specific fragments and a large control PCR product. DNA Fragments can be distinguished via electrophoresis on agarose gel.

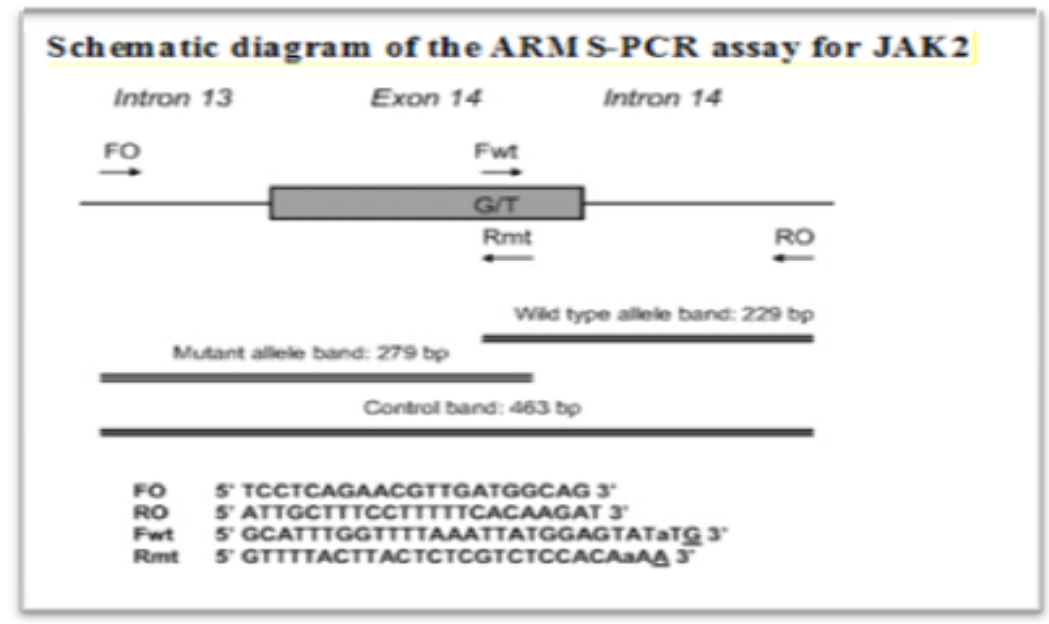

Figure 4. Primer designing for ARMS-PCR assay of JAK2V 617F Mutation

Performing a dilution series indicates the level of sensitivity of ARMS-PCR to be 1-2 \%. The assay allows discrimination between homozygous and heterozygous individuals with the JAK2 V617F mutation and has a key role in acting as a reliable screening test for the presence or absence of the mutation in individuals with MPDs. An acquired mutation in the JAK2 gene is a cytoplasmic tyrosine kinase that plays an essential role in the signaling pathways of cytokines and growth factors. The mutation $1849 \mathrm{G}>\mathrm{T}$, which leads to amino acid substitution of phenylalanine for a highly conserved valine (V617F), (as shown in figure 5) renders JAK2 kinase constitutively active and leads to cell proliferation in the absence of the growth factors 


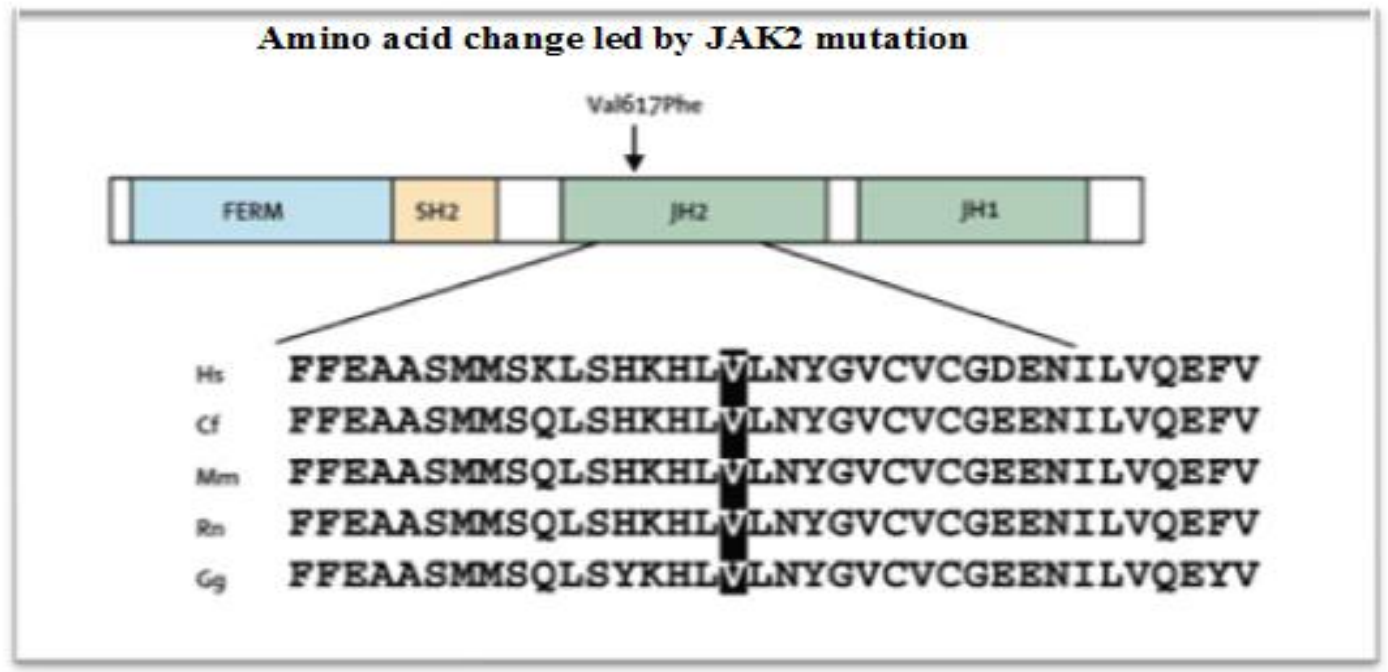

Figure 5. Primer designing for ARMS-PCR assay of JAK2V 617F Mutation

The study was conducted on 50 specimens 25 were controls and 25 were MPD cases. The 25 newly diagnosed MPD patients among which 17 were polycythemia vera, 5 Essential thrombocytopenia and 3 primary myelofibrosis and 25 healthy controls depicted in figure 6 . Both cases and controls were tested for JAK2 mutations by ARMS-PCR. The JAK2 mutation was detected in 17/25 samples among which 13 were Polycythemia Vera, 02 from Essential thrombocythemia, 01 from Primary myelofibrosis as depicted in figure 7. The JAK2 mutation was not detected in any of the healthy controls by ARMS-PCR.

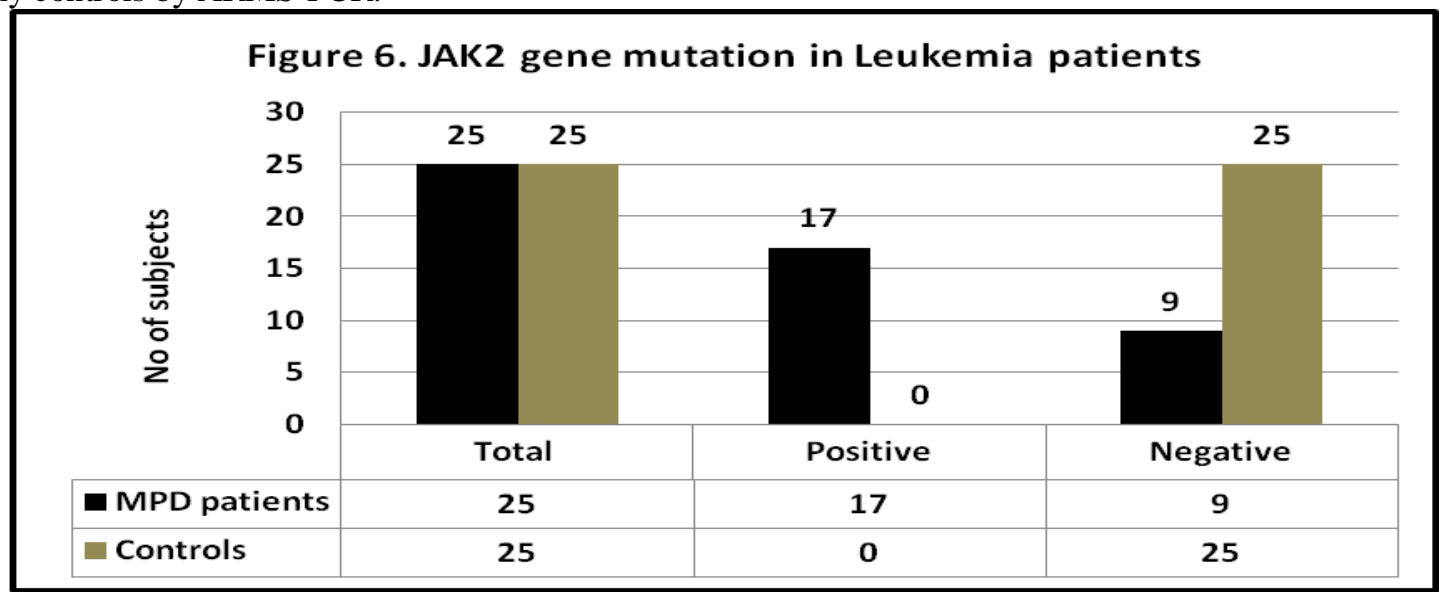




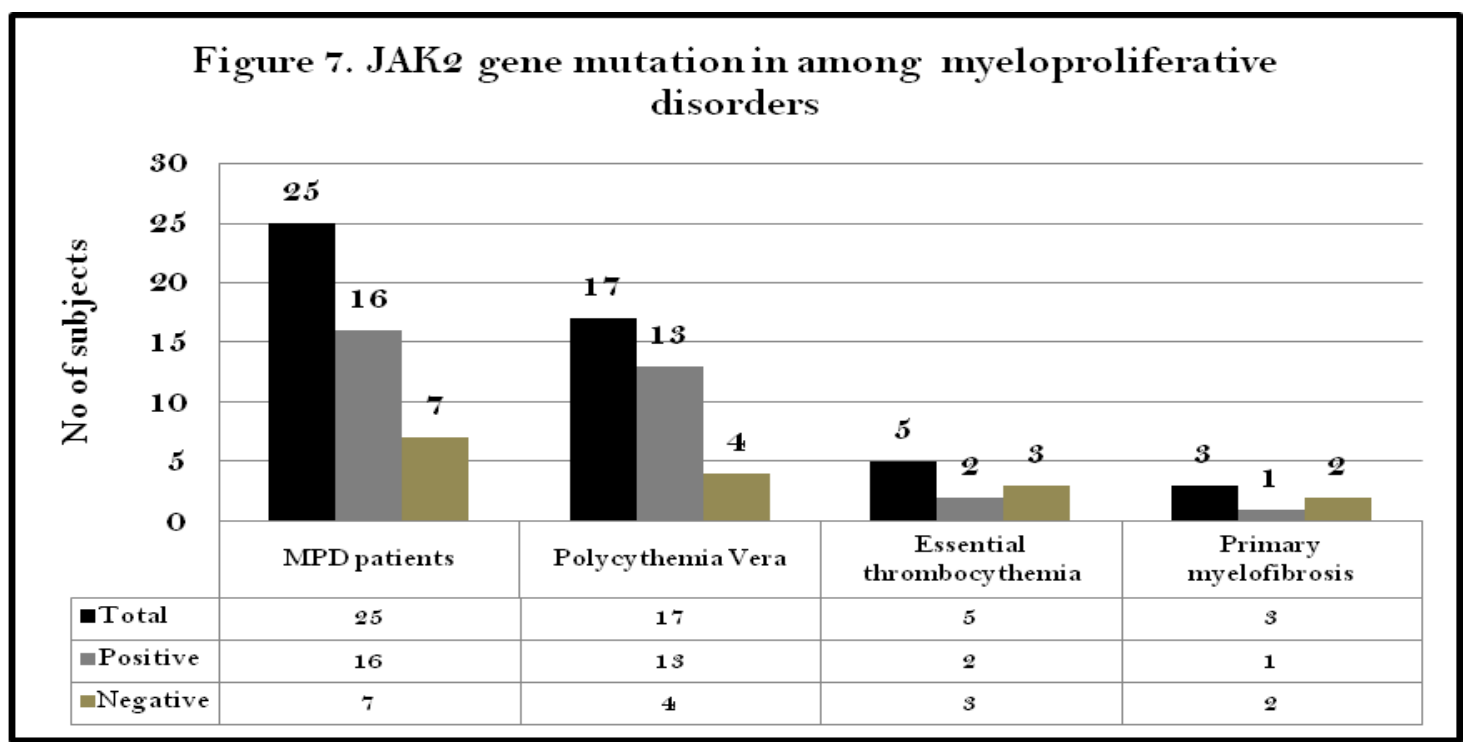

JAK2 V617F - DNA Reference Standards (Horizon diagnostics) for wild as well as mutant allele were used along with ARMS-PCR assays. ARMS assay proved to be highly sensitive technique and can be used to monitor residual disease after treatment. The JAK2 mutation was discovered using direct sequencing after PCR. However, the method only detects the mutation present in more than 20 to $30 \%$ of total DNA. The JAK2 mutation has become an important diagnostic criterion for Philadelphia chromosome-negative myeloproliferative neoplasms (Ph-neg MPN), especially in polycythemia vera (PV). ${ }^{19}$ accordingly, it has been included in the World Health Organization diagnostic criteria for Phneg $\mathrm{MPN}^{20}$.In Jak2 gene new exon 12 mutations involved in the pathogenesis of PV and idiopathic erythrocytosis have been described. These mutations are also important for the diagnosis of PV, as approximately $3 \%$ of PV cases have mutations in this exon. ${ }^{21}$ In addition, other JAK2 exon 14 mutations that are distinct from JAK2 V617F, such as C616Y, D620E, and C618R, have been detected in patients with myoproliferative neoplasms (MPN). ${ }^{22}$ Despite this, the described JAK2 mutations are neither specific for this group of diseases, nor are they present in all patients with classical $\mathrm{Ph}$-neg MPN (especially in essential thrombocythemia [ET] and primary myelofibrosis). In addition, infrequent occurrence of the JAK2 V617F mutation has been reported in chronic myelomonocytic leukemia, atypical MPN, myelodysplastic syndromes, systemic mastocytosis, and acute myeloid leukemia. ${ }^{23}$ Detection of the mutation is helpful in differential diagnosis, prognosis, and predication of therapeutic response.

Amplification Refractory Mutation System (ARMS-PCR) has also been termed allele-specific PCR or PCR amplification of specific alleles (PASA). The amplification refractory mutation system (ARMS) is an amplification strategy in which a polymerase chain reaction (PCR) primer is designed in such a way that it is able to discriminate among templates that differ by a single nucleotide residue .Thus, an ARMS primer can be designed to amplify a specific member of a multi-allelic system while remaining refractory to amplification of another allele that may differ by as little as a single base from the former.

Several laboratory techniques have been developed for JAK2 V617F genotypic analysis. Because JAK2 mutation is an acquired mutation that can be present in a small proportion of granulocytic populations in some cases, especially of ET, a highly sensitive detection method is essential. Different sensitivity of various assay methods partially accounts for the wide range of mutation frequencies reported in the literature. ${ }^{23}$ As a matter of fact, re-evaluation of the same cases with a more sensitive technique has increased the detection rate from 73 to $97 \%$ in patients with polycythemia vera. ${ }^{24}$ In addition, a highly sensitive technique is potentially useful to monitor residual disease after treatment. Methodologies reported in the literature include direct sequencing, ${ }^{24}$ allele-specific polymerase chain reaction (PCR), ${ }^{24}$ PCR-restriction fragment length polymorphism, ${ }^{25}$ pyrosequencing, ${ }^{26}$ and amplification refractory mutation system (ARMS)-PCR ${ }^{26}$..The main advantage of ARMS is that the amplification step and the diagnostic steps are combined, in that the presence of an amplified product indicates the presence of a particular allele and vice versa. For routine diagnosis, this characteristic of ARMS means that it is a very time-efficient method. However, this combination of the amplification and diagnostic steps has resulted in a system that may not be as robust as some of the other methods in which these two important steps are separated, e.g., PCR followed by restriction enzyme analysis. Moreover, the data show that direct sequencing is not an adequate technique for exon 12 mutation identification; therefore, appropriate methodology should be considered for using this molecular marker in the process of diagnosis. It has been have demonstrated that this high sensitivity is not 
accompanied by any significant compromise in the diagnostic specificity of the assay. In addition, the ARMS-PCR assay shows different patterns for normal, mutant, or mixed genotypes, minimizing the chance of misinterpretation. With simply one tube of PCR reactions and obviation for special equipment and reagents, ARMS-PCR represents a time- and labor-saving as well as cost-efficient method that is readily and broadly applicable in clinical molecular diagnostic laboratories.

Conclusion:-.

It was concluded that the ARMS-PCR assay is an appropriate methodology should be considered for using JAK2 molecular marker in the process of MPD diagnosis and allows discrimination between homozygous and heterozygous individuals with the JAK2 (V617F and in exon 12) mutation and has a key role in acting as a reliable screening test for the presence or absence of the mutation in individuals with MPDs. The test is therefore a simple, fast, and inexpensive procedure that does not entail any special equipment other than a thermocycler.

\section{Competing interests:-}

- The authors declare that they have no competing interests.

Authors' contributions:-

* All authors read and approved the final manuscript. Thanks to all authors for their support and help in this study.

\section{ACKNOWLEDGMENTS:-}

* We would like to acknowledge the assistance of Mr Anan Ishtiah and Mohammad Imran Uddin.

\section{Grant support}

* This work was supported by grants from the Deanship of Scientific Research (1430-0269), University of Tabuk. Saudi Arabia.

\section{References:-}

1. Dameshek W. Some speculations on the myeloproliferative syndromes. Blood1951; 6: 372-375.

2. Nelson ME, Steensma DP (2006) JAK2 V617F in myeloid disorders: what do we know now, and where are we headed? Leuk Lymphoma 47: 177-194.

3. Goldman JM, Melo JV. Chronic myeloid leukemia - advances in biology and new approaches to treatment. $N$ Engl J Med 2003; 349: 1451-1464.

4. Deininger M, Buchdunger E, Druker BJ. The development of imatinib as a therapeutic agent for chronic myeloid leukemia. Blood 2005; 105: 2640-2653.

5. Greiner, TC. Diagnostic assays for the JAK2 V617F mutation in chronic myeloproliferative disorders. Am $J$ Clin Pathol. 2006; 125: 651-653

6. Levine RL, Wadleigh M, Cools J, Ebert BL, Wernig G, Huntly BJ et al. Activating mutation in the tyrosine kinase JAK2 in polycythemia vera, essential thrombocythemia, and myeloid metaplasia with myelofibrosis. Cancer Cell 2005; 7: 387-397.

7. James C, Ugo V, Le Couedic JP, Staerk J, Delhommeau F, Lacout C et al. A unique clonal JAK2 mutation leading to constitutive signalling causes polycythaemia vera. Nature 2005; 434: 1144-1148.

8. Kralovics R, Passamonti F, Buser AS, Teo SS, Tiedt R, Passweg JR, Tichelli A, Cazzola M, Skoda RC. A gain-offunction mutation of JAK2 in myeloproliferative disorders. N Engl J Med.2005;352:1779-1790

9. Vainchenker W, Constantinescu SN. A unique activating mutation in JAK2 (V617F) is at the origin of polycythemia vera and allows a new classification of myeloproliferative diseases. Hematology (Am Soc Hematol Educ Program) 2005:195-200.

10. Campbell PJ, Scott LM, Buck G, Wheatley K, East CL, Marsden JT, Duffy A, Boyd EM, Bench AJ, Scott MA, Vassiliou GS, Milligan DW, Smith SR, Erber WN, Bareford D, Wilkins BS, Reilly JT, Harrison CN, Green AR, United Kingdom Myeloproliferative Disorders Study Group, Medical Research Council Adult Leukaemia Working Party, Australasian Leukaemia and Lymphoma Group .Definition of subtypes of essential thrombocythaemia and relation to polycythaemia vera based on JAK2 V617F mutation status: a prospective study. Lancet. 2005 Dec 3; 366(9501):1945-53.

11. McClure R, Mai M, Lasho T. Validation of two clinically useful assays for evaluation of JAK2 V617F mutation in chronic myeloproliferative disorders. Leukemia. 2006;20:168

12. Jelinek J, Oki Y, Gharibyan V, Bueso-Ramos C, Prchal JT, Verstovsek S, Beran M, Estey E, Kantarjian HM, Issa JP. JAK2 mutation $1849 \mathrm{G}>\mathrm{T}$ is rare in acute leukemias but can be found in CMML, Philadelphia chromosomenegative CML, and megakaryocytic leukemia. Blood.2005;106:3370-3373 
13. Steensma, DP. JAK2 V617F in myeloid disorders: molecular diagnostic techniques and their clinical utility: a paper from the 2005 William Beaumont Hospital Symposium on Molecular Pathology. J Mol Diagn. 2006; 8: 397411

14. Steensma DP. JAK2 V617F in myeloid disorders: molecular diagnostic techniques and their clinical utility: a paper from the 2005 William Beaumont Hospital Symposium on Molecular Pathology. J Mol Diagn. 2006;8:397-411

15. Ma W, Kantarjian H, Zhang X, Yeh C-H, Zhang ZJ, et al. Mutation profile of JAK2transcripts in patients with chronic myeloproliferative neoplasias. J Mol Diagn 2009, 11: 49-53.

16. McClure R, Mai M, Lasho T. Validation of two clinically useful assays for evaluation of JAK2 V617F mutation in chronic myeloproliferative disorders. Leukemia. 2006;20:168-171

17. Tefferi A, Sirhan S, Lasho TL, Schwager SM, Li CY, Dingli D et al. Concomitant neutrophil JAK2 mutation screening and PRV-1 expression analysis in myeloproliferative disorders and secondary polycythaemia. $\mathrm{Br} J$ Haematol 2005; 131: 166-171.

18. Vannucchi AM, Guglielmelli P, Antonioli E, Mappa S, Pancrazzi A, Bogani C et al. Inconsistencies in the association between the JAK2 mutation and PRV-1 over-expression among the chronic myeloproliferative diseases. Br J Haematol 2006; 132: 652-654.

19. James, C, Ugo, V, Le Couedic, JP, Staerk, J, Delhommeau, F, Lacout, C, Garcon, L, Raslova, H, Berger, R, Bennaceur-Griscelli, A, Villeval, JL, Constantinescu, SN, Casadevall, N, and Vainchenker, W. A unique clonal JAK2 mutation leading to constitutive signalling causes polycythaemia vera. Nature. 2005;434: 1144-1148

20. Tefferi, A, Thiele, J, Orazi, A, Kvasnicka, HM, Barbui, T, Hanson, CA, Barosi, G, Verstovsek, S, Birgegard, G, Mesa, R, Reilly, JT, Gisslinger, H, Vannucchi, AM, Cervantes, F, Finazzi, G, Hoffman, R, Gilliland, DG, Bloomfield, CD, and Vardiman, JW. Proposals and rationale for revision of the World Health Organization diagnostic criteria for polycythemia vera, essential thrombocythemia, and primary myelofibrosis: recommendations from an ad hoc international expert panel. Blood. 2007; 110: 1092-1097

21. Pietra, D, Li, S, Brisci, A, Passamonti, F, Rumi, E, Theocharides, A, Ferrari, M, Gisslinger, H, Kralovics, R, Cremonesi, L, Skoda, R, and Cazzola, M. Somatic mutations of JAK2 exon 12 in patients with JAK2 (V617F)negative myeloproliferative disorders. Blood. 2008; 111: 1686-1689

22. Grunebach, F, Bross-Bach, U, Kanz, L, and Brossart, P. Detection of a new JAK2 D620E mutation in addition to V617F in a patient with polycythemia vera. Leukemia. 2006; 20: 2210-2211

23. Tefferi, A and Pardanani, A. Mutation screening for JAK2V617F: when to order the test and how to interpret the results. Leuk Res. 2006; 30: 739-744

24. Baxter, EJ, Scott, LM, Campbell, PJ, East, C, Fourouclas, N, Swanton, S, Vassiliou, GS, Bench, AJ, Boyd, EM, Curtin, N, Scott, MA, Erber, WN, and Green, AR. Acquired mutation of the tyrosine kinase JAK2 in human myeloproliferative disorders. Lancet. 2005; 365:1054-1061

25. Levine, RL, Wadleigh, M, Cools, J, Ebert, BL, Wernig, G, Huntly, BJ, Boggon, TJ, Wlodarska, I, Clark, JJ, Moore, S, Adelsperger, J, Koo, S, Lee, JC, Gabriel, S, Mercher, T, D'Andrea, A, Frohling, S, Dohner, K, Marynen, P, Vandenberghe, P, Mesa, RA, Tefferi, A, Griffin, JD, Eck, MJ, Sellers, WR, Meyerson, M, Golub, TR, Lee, SJ, and Gilliland, DG.Activating mutation in the tyrosine kinase JAK2 in polycythemia vera, essential thrombocythemia, and myeloid metaplasia with myelofibrosis. Cancer Cell. 2005; 7:387-397

26. Jones, AV, Kreil, S, Zoi, K, Waghorn, K, Curtis, C, Zhang, L, Score, J, Seear, R, Chase, AJ, Grand, FH, White, H, Zoi, C, Loukopoulos, D, Terpos, E, Vervessou, EC, Schultheis, B, Emig, M, Ernst, T, Lengfelder, E, Hehlmann, R, Hochhaus, A, Oscier, D, Silver, RT, Reiter, A, and Cross, NC. Widespread occurrence of the JAK2 V617F mutation in chronic myeloproliferative disorders. Blood. 2005; 106: 2162-2168 